\title{
Impact of Patient Awareness on Access to Transplantation in End Stage Renal Disease
}

\author{
Lina Mackelaite ${ }^{\mathrm{a}, \mathrm{c}}$, Adam E Gaweda ${ }^{\mathrm{a}}$, Ether Muhs ${ }^{\mathrm{b}}$, Rosemary Ouseph ${ }^{\mathrm{a}}$
}

\begin{abstract}
Background: Despite the survival benefit offered by kidney transplantation, only a small percent of hemodialysis patients are on a kidney transplant list.

Methods: We performed a prospective study to assess the impact of patient awareness on access to kidney transplantation. We administered a standardized questionnaire (13 questions) to 129 prevalent end stage renal disease (ESRD) patients undergoing in-center hemodialysis at one large and one small dialysis organization.
\end{abstract}

Results: Discussion of the transplant option with the physician was the only significant factor $(\mathrm{P}=0.003)$ associated with patient's presence on a kidney transplant list or being in the work-up process.

Conclusions: Patient's awareness of renal transplantation after initiation of dialysis plays a major role in their access to transplantation.

Keywords: Kidney; Transplantation; Hemodialysis; Peritoneal dialysis

\section{Introduction}

Kidney transplantation offers end stage renal disease (ESRD) patients greater survival benefit compared to other modalities of renal replacement therapy (RRT), including hemodialysis and peritoneal dialysis [1-3]. Even senior patients (older than 70 years of age) may benefit from kidney transplantation, as their risk of death is $41 \%$ lower when compared to the same

Manuscript accepted for publication April 15, 2014

${ }^{a}$ Department of Medicine, University of Louisville, Louisville, KY, USA

${ }^{\mathrm{b}}$ University Kidney Center, Louisville, KY, USA

${ }^{\mathrm{c} C}$ Corresponding author: Lina Mackelaite, Department of Medicine,

University of Louisville, 615 S. Preston St, Louisville, KY 40202, USA.

Email:10mack01@louisville.edu

doi: http://dx.doi.org/10.14740/wjnu158w age group on the waiting list [4]. Despite that, only $12.5 \%$ of prevalent ESRD patients (12.5\%) are on the transplant list and in 2008 only $21 \%$ of incident patients were added to the transplant waiting list or received a transplant within 1 year after initiation of RRT [2].

Previous studies showed that younger and healthier individuals of higher socioeconomic status are more likely to be selected as potential recipients of a kidney transplant. On the other hand, women, older patients, non-Caucasians and lower income individuals are less likely to receive kidney transplant $[5,6]$. It is also known that poor health literacy is associated with lower referral rates for kidney transplantation [7]. In addition, pre-emptive kidney transplant, which is known to improve transplant outcomes, is more common in Caucasians, patients with higher education and higher income [8].

Also of note there are transplantation rates which vary as much as five times between different hemodialysis units. It remains significant even after adjustment for patient comorbidities and demographic factors [9].

A recent study of 428 incident ESRD patients demonstrated that the major factor determining patient's selection of peritoneal dialysis compared to in-center hemodialysis was the presentation of this dialysis modality as an option prior to starting RRT and the time spent by the physician educating the patient about peritoneal dialysis [10].

To date, no study has addressed patient awareness of transplantation as one of the factors associated with access to renal transplantation. In this manuscript, we address this gap. We present a prospective study to analyze the effect of patient awareness on the access to renal transplantation. Our goal was to identify easily modifiable factors associated with access to renal transplantation in prevalent ESRD patients undergoing in-center hemodialysis. These factors can be used to design subsequent interventions aiming to improve the access to renal transplantation.

\section{Materials and Methods}

\section{Study design}

The study protocol and questionnaires (Fig. 1) conformed to 


\section{Questionnaire}

What factors influence access to renal transplantation in ESRD patients undergoing in-center dialysis?

DOB:

Age:

Ethnicity:

Weight:

RRT since what year:

Education:

$\begin{array}{ll}\square \text { Grade school } & \square \text { Some College } \\ \square \text { High school } & \square \text { Finished College }\end{array}$

Lives:
$\checkmark$ With significant other
$\square$ Alone
口 With children
$\triangle$ Other

Employed:

$\square$ Yes

$\square$ No

DM:

$$
\begin{aligned}
& \square \text { Yes } \\
& \square \text { No }
\end{aligned}
$$

1. Did your dialysis doctor talk to you about kidney transplantation?

$$
\begin{aligned}
& \square \text { Yes } \\
& \square \text { No }
\end{aligned}
$$

2. Do you think you were provided with enough information to make an informed decision about renal transplantation?

$$
\begin{aligned}
& \square \text { Yes } \\
& \square \text { No }
\end{aligned}
$$

3. Are you on a transplant list?

$\square$ Yes (if yes, go to question No 6)

$\square$ No (if no, go to question No 5)

4. Are you being evaluated for a kidney transplant?

- Yes (if yes, go to question No 6)

$\square$ No (if no, go to question No 5)

5. Why are you not being worked up for a transplant/not on the list?

- You are too sick

$\square$ Nobody talked to you about it

$\checkmark$ You do not want a transplant

o Other

6. Do you know any people who have/ or had a kidney transplant?

$\square$ Yes (if yes, go to question No 7)

$\square$ No (if no, go to question No 8)

7. Is that person happy he got the transplant?

$$
\square \text { Yes }
$$

$\square$ No

8. Do you think people live longer if they get a kidney transplant?

$$
\begin{aligned}
& \square \text { Yes } \\
& \square \text { No }
\end{aligned}
$$

9. Would you go to a class about kidney transplantation if such was offered to you?

$$
\begin{aligned}
& \square \text { Yes } \\
& \square \text { No }
\end{aligned}
$$

10. Do you think a living person can donate a kidney to a patient on dialysis?

$$
\begin{aligned}
& \square \text { Yes } \\
& \square \text { No }
\end{aligned}
$$

11. Do you think that renal transplant surgery is very risky and you may get a lot of complications from it?

$$
\begin{aligned}
& \square \text { Yes } \\
& \square \text { No }
\end{aligned}
$$

12. Did you discuss treatment options with your doctor before starting hemodialysis (e.g. peritoneal dialysis, kidney transplant, home dialysis)?

$$
\begin{aligned}
& \square \text { Yes } \\
& \square \text { No }
\end{aligned}
$$

13. Generally speaking, how satisfied are you with hemodialysis?

$$
\begin{aligned}
& \square \text { Very satisfied } \\
& \square \text { Somewhat satisfied } \\
& \square \text { Not satisfied }
\end{aligned}
$$

Figure 1. Study questionnaire. 
the Declaration of Helsinki and were approved by Institutional Review Board (IRB) of University of Louisville. The data collection was conducted between May 2011 and November 2011. We interviewed a total of 129 prevalent ESRD patients undergoing in-center hemodialysis treatments three times a week at one large dialysis organization (LDO) unit (DSI) and one non-LDO unit (Kidney Disease Program, University of Louisville) in Louisville. Informed consent was obtained from each individual before participation in the study. All personal health information data remained confidential. The questionnaires were administered by either, a dialysis nurse practitioner, or qualified research personnel. To achieve better compliance and to prevent information loss and misinterpretation due to potential disabilities of the study participants, the questionnaires were administered verbally to the subjects. An initial survey was first conducted with five pilot questionnaires. The final questionnaire was developed based on the results of this pilot study. A total of 217 patients were enrolled in the study and completed the questionnaires (remaining patients either declined the consent or were unavailable during the study). Demographic data were also obtained from Centers for Medicaid and Medicare Services (CMS) Medical Evidence Form 2728.

\section{Statistical analysis}

Statistical analysis was performed using SPSS (version 8.2, SPSS, Inc., Chicago, IL, USA). We developed a binary logistic regression model to evaluate predictors of being on the transplant list or in the process of work-up for a transplant (positive outcome). We used Hosmer \& Lemeshow model selection method [7] to select the most influential predictors (with initial threshold $\mathrm{P} \leq 0.3$ for the univariate model and $\mathrm{P} \leq 0.05$ for the final multivariate model). Factors that were included in the univariate model where: age, weight, dialysis vintage, level of education, employment status, ethnicity (Caucasian vs. others), comorbidities (diabetes, coronary artery disease), having discussed transplantation with dialysis physician, having discussed transplantation with nephrologist prior to initiating RRT, knowing a kidney transplant recipient, being aware of survival benefit of getting a transplant versus remaining on hemodialysis (knowing benefit of renal transplantation) and satisfaction with hemodialysis.

\section{Results}

Results of the statistical analysis are presented in Table 1. Thirteen percent of study participants were active on a transplant list and $11 \%$ were in the process of finishing work-up to be listed. Seventy-seven percent of all our dialysis patients were African Americans. Thirty-three percent of patients stated that their dialysis physician never discussed an option of kidney transplantation with them. In the univariate analysis, the factors associated with a higher likelihood of being on a transplant list were: discussing renal transplantation with the nephrologist after RRT initiation (OR 21.5, P $=0.003$ ), presentation of different treatment options prior to starting hemodialysis (OR 3.15, $\mathrm{P}=0.05$ ), knowing a kidney transplant recipient (OR 1.7, $\mathrm{P}=0.27$ ) and being aware of the benefits of kidney transplantation ( OR 1.7, P = 0.23). Interestingly, the employment status, the presence of diabetes mellitus as the major comorbidity for ESRD and age, which were previously associated with earlier presentation of transplantation [10], were not associated with being on a transplant list or evaluated for a transplant in our study. In the multivariate analysis, the only factor that was significantly associated with being on a transplant list (or being in a workup process) was having discussed renal transplantation with nephrologist after initiation of RRT (OR 19, $\mathrm{P}=0.005)$.

Only $48 \%$ of people with hemodialysis vintage of less than 1 year remembered having a discussion about renal transplantation with their nephrologist compared to $73 \%$ of patients who were on dialysis for more than 1 year. This is a concerning observation since it is known that dialysis vintage does affect patient survival after kidney transplantation [11]. Longer dialysis vintage is also associated with worse graft survival and higher rates of rejection [12].

When asked about the reason why they were not on a transplant list, six $(5 \%)$ patients did not know the reason. Nine $(7.5 \%)$ patients reported a reason that is not a contraindication for a transplant (age, hepatitis $\mathrm{C}$ infection or not being on dialysis long enough), and five patients stated that they did not want to get a transplant (they either knew someone who did not do well after transplantation or did not want to undergo evaluation).

\section{Discussion}

Transplantation offers a survival advantage to people with ESRD compared to other treatment modalities. Unfortunately, only a small percent of patients with renal failure are on the transplant list. Our goal was to identify easily modifiable factors associated with access to transplantation. We found that making the patient aware of the transplant option after initiation of dialysis was the most important factor associated with being listed or being in the process of work-up for a kidney transplant. Another important finding in our study was that the transplant option is being presented to only a fraction of in-center hemodialysis patients and that it is being done long after the initiation of dialysis. A third of the study subjects stated that their physician never discussed the possibility of transplantation with them.

There may be multiple potential reasons why patients do not get educated about kidney transplantation early after starting hemodialysis. This study was conducted in dialysis units that serve mainly inner city low income population. 
Table 1. Characteristics of Patients on Kidney Transplant List (or in the Process of Transplant Work-up) and Patients Not on the List

\begin{tabular}{|c|c|c|c|c|}
\hline & \multicolumn{2}{|l|}{ On the list } & \multicolumn{2}{|l|}{ Model } \\
\hline & Yes & No & Odds ratio & P value \\
\hline Number of cases & 31 & 98 & & \\
\hline Age mean (SD) & $54(9.6)$ & $55(11.9)$ & 0.988 & 0.49 \\
\hline $\begin{array}{l}\text { Dialysis vintage } \\
\text { Median (inter-quartile ra }\end{array}$ & $4(7)$ & $4(6)$ & 1.025 & 0.54 \\
\hline Weight mean (ST) & 177 (45.9) & $178(47.9)$ & 1.000 & 0.93 \\
\hline \multicolumn{5}{|l|}{ Diabetes $(\%)$} \\
\hline Yes & $11(35.5)$ & $37(37.8)$ & 1.103 & 0.82 \\
\hline No & $20(64.5)$ & $61(62.2)$ & 0.907 & \\
\hline \multicolumn{5}{|l|}{ Education (\%) } \\
\hline Grade school & $2(6.5)$ & $5(5.1)$ & 1.000 & 0.76 \\
\hline High school & $15(48.4)$ & $59(60.2)$ & 0.636 & 0.61 \\
\hline Some college & $12(38.7)$ & $26(26.5)$ & 1.154 & 0.87 \\
\hline Finished college & $2(6.5)$ & $5(5.1)$ & 1.000 & $>0.99$ \\
\hline Post graduate & $0(0.0)$ & $3(3.1)$ & 0.000 & $>0.99$ \\
\hline \multicolumn{5}{|l|}{ Employment (\%) } \\
\hline Yes & 4 (12.9) & $8(8.2)$ & 1.667 & 0.43 \\
\hline No & $27(87.1)$ & $90(91.8)$ & 0.600 & \\
\hline \multicolumn{5}{|l|}{ Ethnicity (\%) } \\
\hline African American & $22(22.2)$ & $77(77.8)$ & 0.667 & 0.38 \\
\hline Other & $7(26.9)$ & $19(73.1)$ & 1.500 & \\
\hline \multicolumn{5}{|c|}{ MD talked about transplant? (\%) } \\
\hline Yes & $30(96.8)$ & $57(58.2)$ & 21.579 & $0.003 *$ \\
\hline No & $1(3.2)$ & $41(41.8)$ & 0.046 & \\
\hline \multicolumn{5}{|c|}{ Do you know kidney transplant recipient? (\%) } \\
\hline Yes & $21(67.6)$ & $54(55.1)$ & 1.711 & $0.216^{*}$ \\
\hline No & $10(32.3)$ & $44(44.9)$ & 0.584 & \\
\hline \multicolumn{5}{|c|}{ Do transplant recipients live longer? (\%) } \\
\hline Yes & $20(64.5)$ & $50(51.5)$ & 1.709 & $0.209 *$ \\
\hline No & $11(35.5)$ & $47(48.5)$ & 0.585 & \\
\hline \multicolumn{5}{|c|}{ Did you discuss treatment options prior to HD? (\%) } \\
\hline Yes & $26(83.9)$ & $61(62.2)$ & 3.154 & $0.030 *$ \\
\hline No & $5(16.1)$ & $37(37.8)$ & 0.317 & \\
\hline \multicolumn{5}{|c|}{ How satisfied are you with HD? (\%) } \\
\hline Very satisfied & $19(61.3)$ & $50(51.0)$ & 1.000 & 0.57 \\
\hline Somewhat satisfied & $11(35.5)$ & $42(42.9)$ & 0.689 & 0.39 \\
\hline Not satisfied & $1(3.2)$ & $6(6.1)$ & 0.439 & 0.46 \\
\hline
\end{tabular}

${ }^{*}$ Covariates selected for multivariate model $(\mathrm{P}<0.3)$. 
These patients often have no access to medical care prior to starting hemodialysis and present with advanced renal disease when renal replacement therapy has to be initiated as an emergency. Many times these patients have no insurance at the initiation of hemodialysis which may play a role in delaying the discussion about transplantation.

The study has several limitations. The study only involved the ESRD patients, therefore, we were unable to interview the subjects' nephrologists about reasons for not discussing the transplant option with their patients. Although it is a requirement that all dialysis patients have to be presented with a possibility of transplantation, occasionally physicians may decide that the patient may not be a transplant candidate due to their comorbidities or overall health status.

\section{Conclusion}

Patients who are made aware of transplantation by their physician after the initiation of hemodialysis are more likely to be listed for a kidney transplant. However, more than $30 \%$ of ESRD patients that undergo in-center hemodialysis are never made aware of the option of transplantation or there is a delay. We postulate the introduction of a standardized protocol that addresses timing and content of such discussions between dialysis physicians and their patients would improve the access to transplantation.

\section{Financial Support}

None of the authors received any financial or other support related to this study.

\section{Conflict of Interest}

None of the authors have any financial interests associated with this study.

\section{References}

1. Wolfe RA, Ashby VB, Milford EL, Ojo AO, Ettenger RE, Agodoa LY, Held PJ, et al. Comparison of mortality in all patients on dialysis, patients on dialysis awaiting transplantation, and recipients of a first cadaveric transplant. N Engl J Med. 1999;341(23):1725-1730.

2. Mazzuchi N, Gonzalez-Martinez F, Carbonell E, Curi L, Fernandez-Cean J, Orihuela S. Comparison of survival for haemodialysis patients vs renal transplant recipients treated in Uruguay. Nephrol Dial Transplant. 1999;14(12):2849-2854.

3. Pauly RP, Gill JS, Rose CL, Asad RA, Chery A, Pierratos A, Chan CT. Survival among nocturnal home haemodialysis patients compared to kidney transplant recipients. Nephrol Dial Transplant. 2009;24(9):2915-2919.

4. Rao PS, Merion RM, Ashby VB, Port FK, Wolfe RA, Kayler LK. Renal transplantation in elderly patients older than 70 years of age: results from the Scientific Registry of Transplant Recipients. Transplantation. 2007;83(8):1069-1074.

5. Gaylin DS, Held PJ, Port FK, Hunsicker LG, Wolfe RA, Kahan BD, Jones CA, et al. The impact of comorbid and sociodemographic factors on access to renal transplantation. JAMA. 1993;269(5):603-608.

6. Ayanian JZ, Cleary PD, Weissman JS, Epstein AM. The effect of patients' preferences on racial differences in access to renal transplantation. N Engl J Med. 1999;341(22):1661-1669.

7. Hosmer DW, Lemeshow S. Applied Logistic Regression. New York. Wiley, 2000.

8. Kasiske BL, London W, Ellison MD. Race and socioeconomic factors influencing early placement on the kidney transplant waiting list. J Am Soc Nephrol. 1998;9(11):2142-2147.

9. Alexander GC, Sehgal AR. Variation in access to kidney transplantation across dialysis facilities: using process of care measures for quality improvement. Am J Kidney Dis. 2002;40(4):824-831.

10. Mehrotra R, Marsh D, Vonesh E, Peters V, Nissenson A. Patient education and access of ESRD patients to renal replacement therapies beyond in-center hemodialysis. Kidney Int. 2005;68(1):378-390.

11. Schold JD, Meier-Kriesche HU. Which renal transplant candidates should accept marginal kidneys in exchange for a shorter waiting time on dialysis? Clin J Am Soc Nephrol. 2006;1(3):532-538.

12. Mange KC, Joffe MM, Feldman HI. Effect of the use or nonuse of long-term dialysis on the subsequent survival of renal transplants from living donors. N Engl J Med. 2001;344(10):726-731. 